\title{
Trends of Fast Food Consumption among Public University Students
}

\author{
Sharhida Zawani S. ${ }^{1}$, Nor Hazlyna, H. ${ }^{2}$, Rifqiandra Muhammad ${ }^{3}$, Umi Madihah Mohamed Raimi ${ }^{4}$, \\ Hasan S M Mehedi ${ }^{5}$, Adegustami Rizky Harsa ${ }^{6}$ \\ 1,2,3,4,5,6 School of Computing, College of Arts \& Sciences, Universiti Utara Malaysia, Sintok, Kedah, Malaysia \\ hazlyna@uum.edu.my ${ }^{2}$
}

Article History: Received: 10 November 2020; Revised: 12 January 2021; Accepted: 27 January 2021; Published online: 05 April 2021

\begin{abstract}
Purpose: This study aims to increase the awareness of fast food impact on body health and overweight status among public university students. Materials \& methods: The sample size consists of 100 students of a public university. Data collection was conducted via an online survey. A survey was conducted by employing questionnaire and administered online. The questionnaire asked the students about their fast food consumption patterns that consist of their preferences, and trends of consumption. Result: The study demonstrates that one of the most popular fast food joints among public university students was McDonald's (51\%\%). Majority of the respondents consume fast food only once or twice in a month $(67 \%)$ and most of them consume fast food as a meal $(67 \%)$. Conclusion: The overall findings indicate that public university students' fast food level of intake is not impacted by their perceptions on fast food.

Keywords: Fast food consumption, Perception, Health, Student, University.
\end{abstract}

\section{Introduction}

Food is one of the biological needs of human beings for survival (Mirkarimi, Mansourian, Kabir, Hosseini, Qorbani \& Davaji, 2016). Abundance of fast food is deemed as a threat to health. Regular consumption of fast food increases obese as well as sickness. Awareness on fast food harmful effects need to be instilled among adults as well as youth and children. This unhealthy food is currently available in many forms. Most of these foods have harmful effects on the human body as the consumption fast food is about more than just food to be consumed, but is deemed as a culture, especially among students (Garza, Ding, Owensby, \& Zizza , 2016). Although the society realise that over consumption of fast food can be dangerous, admirable advertisements and attractive offers on print and online platforms by fast food joints have led to from the inability to recognize negative effects of over consumption of fast food (Brindal, Wilson, Mohr, \& Wittert, 2015).

Fast food is prepared and made available by restaurants or stores with a strong priority placed on "speed of service" and is presented in a neatly packaged product (Oexle, Barnes, Blake, Bell, \& Liese, 2015). Besides that, the phenomenon in having to eat away from home continues to increase and has become more noticeable. New branches of fast food are made available at more strategic locations; these include around educational institutions, hospitals, gas stations, marketplaces, terminals and others (Ismail, 2016). The success of fast food is evident in the deep interest in the consumption of fast food by the society (Adam, 2016). They can easily infiltrate foreign markets using various ways of globalization strategies. Based on research conducted, attention by students on their food intake is very important, because it affects the students' physical and mental development, which is regarded as an important asset advancing of human resources. As students' day to day schedule is rather hectic due to pack class schedules and back-to-back assignments, students end up eating on the go than eating clean, opting for fast food as it saves their time and simplifies their lives (De Piero, Bassett, Rossi \& Samman, 2015).

\section{Materials \& Methods}

\subsection{Study Design}

This study assessed university students' perception on impact of fast food consumption. The quantitative research method is used to identify trends of fast food consumption among public university students. 


\subsection{Sample Size}

The sample size is 100 students from a public university. The respondents are students aged 18 years and above. As there are some fast food restaurants around public university and easily accessible, thus, fast food joints are the preferred joints that the students patronise. The selection criteria are students from semester 1 to semester 7 of study terms.

\subsection{Questionnaire and Measurement}

This study uses an online survey for data collection, collected through a questionnaire distributed among the respondents. Respondents were asked about their trend of fast food consumption; this include their preferences, monthly fast food expenditure and intake or consumption pattern. The questionnaire for the respondents was in the Google form format. The forms that were used in the questionnaire were multiple choice and 5-point Likert scale. This survey uses (1) strongly disagree, (2) disagree, (3) neutral, (4) agree, and (5) strongly agree as the scale options. One hundred students participated the survey, between three to five minutes duration of time. For data analysis purpose, the results are formed in a statistical format and collected data are exported to an Excel format. Essential demographic information collected includes the gender, race, age, semester, and residential hall, which serve as the background information of respondents.

\subsection{Fast food consumption}

Fast food is described as food that can be served quickly. Some examples of fast food joints are McDonalds, KFC, Pizza Hut, Burger King, and Subway. The consumption of fast food was studied by frequency of consuming fast food, persons with whom the participants consume fast food, and the purpose the respondents consume fast food.

\section{Results}

\subsection{Sample characteristics}

Table 1. Sample characteristics

\begin{tabular}{|c|c|c|}
\hline \multicolumn{3}{|c|}{ Gender } \\
\hline & Frequency $(\mathrm{N}=100)$ & Percentage \\
\hline Male & 52 & $52 \%$ \\
\hline Female & 48 & $48 \%$ \\
\hline Total & 100 & $100 \%$ \\
\hline \multicolumn{3}{|c|}{ Race } \\
\hline Malay & 48 & $48 \%$ \\
\hline Indian & 17 & $17 \%$ \\
\hline Chinese & 27 & $27 \%$ \\
\hline Indonesian & 5 & $5 \%$ \\
\hline Kenyan & 1 & $1 \%$ \\
\hline Bangladesh & 2 & $2 \%$ \\
\hline Total & 100 & $100 \%$ \\
\hline \multicolumn{3}{|c|}{ Age Groups } \\
\hline $18-20$ & 7 & $7 \%$ \\
\hline $21-23$ & 64 & $64 \%$ \\
\hline $24-26$ & 28 & $28 \%$ \\
\hline $27-30$ & 0 & $0 \%$ \\
\hline Over 30 & 1 & $1 \%$ \\
\hline Total & 100 & $100 \%$ \\
\hline \multicolumn{3}{|c|}{ Semester } \\
\hline 1 & 7 & $7 \%$ \\
\hline 2 & 6 & $6 \%$ \\
\hline 3 & 18 & $18 \%$ \\
\hline 4 & 24 & $24 \%$ \\
\hline 5 & 27 & $27 \%$ \\
\hline 6 & 17 & $17 \%$ \\
\hline 7 & 1 & $1 \%$ \\
\hline
\end{tabular}




\begin{tabular}{l}
\hline \multicolumn{3}{|c|}{ Total } \\
\begin{tabular}{|l|c|c|}
\hline \multicolumn{2}{|c|}{ Residential Hall } \\
\hline Proton & 20 & $100 \%$ \\
\hline Tradewinds & 7 & $70 \%$ \\
\hline MAS & 1 & $1 \%$ \\
\hline TNB & 13 & $13 \%$ \\
\hline Petronas & 16 & $16 \%$ \\
\hline TM & 13 & $13 \%$ \\
\hline BSN & 5 & $5 \%$ \\
\hline Sime Darby & 8 & $8 \%$ \\
\hline MISC & 1 & $1 \%$ \\
\hline Grantt & 5 & $5 \%$ \\
\hline Muamalat & 0 & $0 \%$ \\
\hline YAB & 3 & $3 \%$ \\
\hline Bank Rakyat & 4 & $4 \%$ \\
\hline SME Bank & 0 & $0 \%$ \\
\hline University Inn & 4 & $4 \%$ \\
\hline Total & $\mathbf{1 0 0}$ & $\mathbf{1 0 0 \%}$ \\
\hline
\end{tabular}
\end{tabular}

Table 1 displays the respondents' characteristics of the study. The respondents consist of 52 male students and 48 female students. Among the respondents, $64 \%$ of the sample belongs to 21-23 years of age, $48 \%$ are Malaysian ranging from semester 5 students (27\%).

\subsection{Patterns of fast food consumption}

Table 2. Patterns of fast food consumption

\begin{tabular}{|l|c|c|}
\hline \multicolumn{3}{|c|}{ What fast food restaurant do you often go to? } \\
\hline McDonald's & Frequency(N=100) & Percentage \\
\hline KFC & 51 & $51 \%$ \\
\hline Pizza Hut & 31 & $31 \%$ \\
\hline Subway & 15 & $15 \%$ \\
\hline Burger King & 2 & $2 \%$ \\
\hline Total & 1 & $1 \%$ \\
\hline \multicolumn{1}{|c|}{ How often do you consume fast food on a weekly basis? } \\
\hline $1-2$ times & 67 & $67 \%$ \\
\hline $3-4$ times & 27 & $27 \%$ \\
\hline $4-5$ times & 5 & $5 \%$ \\
\hline 7 times or more & 1 & $1 \%$ \\
\hline Total & $\mathbf{1 0 0}$ & $\mathbf{1 0 0 \%}$ \\
\hline \multicolumn{3}{|c|}{ Who do you usually eat with? } \\
\hline Friends & 76 & $76 \%$ \\
\hline Brothers/Sisters & 2 & $2 \%$ \\
\hline Alone & 19 & $3 \%$ \\
\hline Parents & 3 & $\mathbf{1 0 0 \%}$ \\
\hline Total & $\mathbf{1 0 0}$ \\
\hline \multicolumn{3}{|c|}{ You always consuming fast food as? } \\
\hline A meal & 67 & $67 \%$ \\
\hline Snack & 33 & $\mathbf{1 0 0 \%}$ \\
\hline Total & $\mathbf{1 0 0}$ & \\
\hline \multicolumn{2}{|c|}{} & \\
\hline
\end{tabular}

Table 2 shows among the fast food consumers, whereby $51 \%$ of the respondents prefer McDonald's, $31 \%$ prefer KFC, $15 \%$ prefer Pizza Hut, $2 \%$ prefer Subway and another 1\% prefer Burger King. Meanwhile, as for frequency, $67 \%$ of the respondents are in-frequent consumers (1-2 times in a week), $27 \%$ of the respondents frequent fast food joints between three to four times in a week, 5\% of the respondents frequent the joints between four to five times in a week, and $1 \%$ of the respondents are the most frequent consumers that patronise the joints seven times and more in a week. Furthermore, $67 \%$ of the respondents consume fast food for a meal, 
while $33 \%$ rather consume fast food as snacks. A majority (76\%) consume fast food with friends, $19 \%$ consume fast food alone, $3 \%$ consume fast food with parents, while $2 \%$ consume fast foods with siblings.

\subsection{Attitude for fast food consumption}

Table 3. Attitude for fast food consumption

\begin{tabular}{|c|c|c|}
\hline \multicolumn{3}{|c|}{ Fast food is familiar to me } \\
\hline & Frequency $(\mathbf{N}=100)$ & Percentage \\
\hline Strongly agree & 42 & $42 \%$ \\
\hline Agree & 54 & $54 \%$ \\
\hline Neutral & 3 & $3 \%$ \\
\hline Disagree & 0 & $0 \%$ \\
\hline Strongly disagree & 1 & $1 \%$ \\
\hline Total & 100 & $100 \%$ \\
\hline \multicolumn{3}{|c|}{ I think that fast food is not good for health } \\
\hline Strongly agree & 55 & $55 \%$ \\
\hline Agree & 33 & $33 \%$ \\
\hline Neutral & 11 & $11 \%$ \\
\hline Disagree & 1 & $1 \%$ \\
\hline Strongly disagree & 0 & $0 \%$ \\
\hline Total & 100 & $100 \%$ \\
\hline \multicolumn{3}{|c|}{ I think that fast food can provide all vital nutrients for us } \\
\hline Strongly agree & 9 & $9 \%$ \\
\hline Agree & 23 & $23 \%$ \\
\hline Neutral & 41 & $41 \%$ \\
\hline Disagree & 14 & $14 \%$ \\
\hline Strongly disagree & 13 & $13 \%$ \\
\hline Total & 100 & $100 \%$ \\
\hline \multicolumn{3}{|c|}{ I think that fast food is delicious } \\
\hline Strongly agree & 49 & $49 \%$ \\
\hline Agree & 48 & $48 \%$ \\
\hline Neutral & 3 & $3 \%$ \\
\hline Disagree & 0 & $0 \%$ \\
\hline Strongly disagree & 0 & $0 \%$ \\
\hline Total & 100 & $100 \%$ \\
\hline \multicolumn{3}{|c|}{ I think that fast food restaurants provide an attractive environment } \\
\hline Strongly agree & 35 & $35 \%$ \\
\hline Agree & 48 & $48 \%$ \\
\hline Neutral & 16 & $16 \%$ \\
\hline Disagree & 0 & $0 \%$ \\
\hline Strongly disagree & 1 & $1 \%$ \\
\hline Total & 100 & $100 \%$ \\
\hline \multicolumn{3}{|c|}{ I think that fast food restaurants are clean } \\
\hline Strongly agree & 39 & $39 \%$ \\
\hline Agree & 46 & $46 \%$ \\
\hline Neutral & 14 & $14 \%$ \\
\hline Disagree & 1 & $1 \%$ \\
\hline Strongly disagree & 0 & $0 \%$ \\
\hline Total & 100 & $100 \%$ \\
\hline \multicolumn{3}{|c|}{ I think that fast food portions are large enough to be full } \\
\hline Strongly agree & 34 & $34 \%$ \\
\hline Agree & 51 & $51 \%$ \\
\hline Neutral & 9 & $9 \%$ \\
\hline Disagree & 6 & $6 \%$ \\
\hline Strongly disagree & 0 & $0 \%$ \\
\hline Total & 100 & $100 \%$ \\
\hline \multicolumn{3}{|c|}{ I think that fast food has a lot of salt } \\
\hline Strongly agree & 35 & $35 \%$ \\
\hline
\end{tabular}




\begin{tabular}{|l|c|c|}
\hline Agree & 41 & $41 \%$ \\
\hline Neutral & 18 & $18 \%$ \\
\hline Disagree & 4 & $4 \%$ \\
\hline Strongly disagree & 2 & $2 \%$ \\
\hline Total & $\mathbf{1 0 0}$ & $\mathbf{1 0 0 \%}$ \\
\hline \multicolumn{2}{|c|}{ I think that fast food has a lot of fat } \\
\hline Strongly agree & 34 & $34 \%$ \\
\hline Agree & 53 & $53 \%$ \\
\hline Neutral & 10 & $10 \%$ \\
\hline Disagree & 3 & $3 \%$ \\
\hline Strongly disagree & 0 & $0 \%$ \\
\hline Total & $\mathbf{1 0 0}$ & $\mathbf{1 0 0 \%}$ \\
\hline \multicolumn{2}{|c|}{ I think that consuming fast food will make me fat } \\
\hline Strongly agree & 36 & $36 \%$ \\
\hline Agree & 49 & $49 \%$ \\
\hline Neutral & 11 & $11 \%$ \\
\hline Disagree & 4 & $4 \%$ \\
\hline Strongly disagree & 0 & $0 \%$ \\
\hline Total & $\mathbf{1 0 0}$ & $\mathbf{1 0 0 \%}$ \\
\hline \multicolumn{2}{|c|}{ I think that fast food has a lot of calories } \\
\hline Strongly agree & 50 & $50 \%$ \\
\hline Agree & 43 & $43 \%$ \\
\hline Neutral & 7 & $7 \%$ \\
\hline Disagree & 0 & $0 \%$ \\
\hline Strongly disagree & $\mathbf{1 0 0}$ & $00 \%$ \\
\hline Total & \multicolumn{2}{|c|}{} \\
\hline
\end{tabular}

Table 3 shows attitudes of respondents in fast food consumption. Almost half of the respondents (42\%) show that they are very familiar with fast food. Half of the respondents $(55 \%)$ strongly agree that fast food might be harmful for them. Some respondents (32\%) agree that fast food provides all important nutrients. Almost all the respondents agree that fast food is delicious to consume. Only $3 \%$ of the respondents thought differently, being neutral about the taste. Many of the respondents stated that they went to fast food joints because of the attractive environment, other than clean surroundings provided. Thirty-five respondents truly believe that fast food restaurants provide an attractive environment for them and 39 respondents thought that fast food restaurant was clean enough to eat. Furthermore, $85 \%$ of the respondents agreed that one portion of the food is sufficient to satisfy their hunger. Fast food contain plenty of salt, fat and calories (Banika, Nahera, Pervezb, \& Hosain, 2020). The findings of this survey is parallel with the aforementioned notion, whereby 76 respondents answered that fast food contains a lot of salt, 87 respondents answered that fast food contains a lot of fat, and almost all the participants $(93 \%)$ believed that fast food comprises of a lot of calories. It is worth to mention that overall, $85 \%$ of the respondents believe in the fact that fast food consumption is not healthy.

\section{Discussion}

This study found that majority of the students from public university are familiar with fast food. The online questionnaire was distributed to 100 public university students. The findings were obtained to identify the influence of fast food towards the students. Students are prone to consume fast food due to the influence of the environment; this includes encouragement from their own friends. It has been discussed that fast food contain plenty of fat, calories, and salt which causes high blood pressure in humans. Fast food consumption promotes heart disease, high saturated fats and low in antioxidants. Moreover, fast food consumption promotes atherosclerosis, or the build-up of cholesterol in the arteries of the heart, which can affect human body and cause heart attacks and stroke. In addition, other types of fast food such as soda is an unhealthy product because it is high in sugar and lacks the basic minerals and nutrients that human body needs (Abraham, Martinez, Salas, \& Smith 2018). Over consumption of fast food for long period of time may lead to serious impact on health i.e. high blood pressure, heart problems, other than being obese or overweight.

The findings of this study indicate that students are high fast food consumers. The results show that $51 \%$ of the respondents prefer McDonald's, 31\% prefer KFC, 15\% prefer Pizza Hut, 2\% prefer Subway and 1\% of the respondents prefer Burger King. In terms of frequency, $67 \%$ frequent between one to two times in a week, $27 \%$ frequent three to four times in a week, $5 \%$ frequent four to five times in a week, and $1 \%$ are most frequent 
consumers with seven times and more in a week. Furthermore, $67 \%$ of the respondents consume fast food for a meal, and 33\% consume fast food as snacks. Meanwhile, a majority (76\%) consume fast food with friends, $19 \%$ consume fast food alone, $3 \%$ consume fast food with parents, and $2 \%$ of the respondents consume fast food with their siblings.

Almost half of the respondents (42\%) indicate that they are very familiar with fast food. Meanwhile, more than half of the respondents $(55 \%)$ strongly agree that fast food might be harmful for them. Some respondents (32\%) agree that fast food can provide all important nutrients for their body. Almost all respondents agree that fast food is delicious to consume. Only $3 \%$ of the respondents thought differently that nothing is special about the taste. Many of the respondents stated that they went to fast food joints because of the attractive environment and they deliberate that these restaurants provide clean dine in surroundings. Thirty-five respondents truly believe that fast food restaurants provide an attractive environment for them and 39 respondents thought that fast food restaurants are clean enough to eat. Furthermore, $85 \%$ of the respondents think that one portion of the food is sufficient to satisfy their hunger. On the other hand, $88 \%$ of the respondents think that fast food is not good for health. It is interesting to point that overall, $85 \%$ of the respondents believe that fast food consumption is not healthy due to high content of salt, fat and calories. This is in line with what is being suggested by Banika, Nahera, Pervezb and Hosain (2020), that fast food contain plenty of salt, fat and calories.

Moreover, $85 \%$ of the respondents believe that fast food consumption causes obesity. The findings demonstrate that respondents consume fast food as a meal rather than snack. By consuming fast food as a meal, they might not consume healthy food such as fruits, eggs, vegetables, meats and fish in ideal amount. Most of the respondents are very familiar to fast food, they posit that fast food consumption is not healthy. Only a few respondents think that fast food is a healthy meal, by agreeing that fast food provides all vital nutrients for them. The findings of this study suggest students' perceptions that fast food contain a lot of fat and high in calories that may lead to obesity. Having said that, students still consume fast food. It is found that the highest students' demanded choice of fast food is McDonald, and the lowest is Burger King. The respondents are rather eager to patronise McDonald, which is the most favourite fast food joint, as compared to other fast food restaurants. On the other hand, students are advised to consume healthy food and exercise regularly in preventing health problems and overweight issues in the future, like the slogan we have always heard, "prevention is better than cure".

\section{Conclusion}

In summary, $67 \%$ of the respondents patronize fast food joints at least one to two times a week and most of them prefer to eat fast food with their friends (76\%). Patronising fast food restaurants with friends has become a habit among students. This indicates that the level of fast food intake among students is not impacted by their awareness on the consequences of the consumption, with regards to health issues or obesity.

Over consumption of fast food may also lead to serious health problems including stroke, diabetes, kidney malfunction and heart disease. To prevent this, students can consume food that contain a lot of vitamins and other important nutrients. Fast food can be consumed, but ideally, not making it as eating habit. It is even better if students put limits to fast food consumption or try to avoid it altogether. Over consumption of fast food and lack of physical activity also causes overweight problem. Furthermore, students must be aware pertaining to their food choices strategies. Ideally, students need to do a lot of physical activities such as jogging, playing badminton or other forms of exercises to prevent them from being obese or overweight. This study concludes that although students are aware that fast food contains a lot of salt, fat and calories, they still hunt for fast food restaurants. It is worth to mention that overall, this study indicates that public university students' perceptions on fast food consumption do not automatically impact the levels of fast food consumption among them.

\section{References}

1. Abraham, S., Martinez, M., Salas, G., \& Smith, J. (2018). College student's perception of risk factors related to fast food consumption and their eating habits. 18-21.

2. Adam, A. (2016). Knowledge, Attitudes and Practices Towards Consumption of Fast Food Among Students of Maldives National University. Doctoral dissertation, Faculty of Health Sciences.

3. Banika, R., Nahera, S., Pervezb, S., \& Hosain, M. (2020). Fast Food Consumption and Obseity Among Urban College Going Adolescents in Bangladehs: a Cross-sectional Study. 
4. Beigi, A. M., Asgarian, A., Moshir, E., Heidari, H., Afrashteh, S., Khazaei, S., \& Ansari , H. (2018). Fast food consumption and overweight/obesity prevalence in students and its assciation with general and abdominal obesity.

5. Brindal, E., Wilson, C., Mohr, P., \& Wittert, G. (2015). Eating in groups: Do multiple social influences affect intake in a fast-food restaurant? . Journal of Health Psychology, 483-489.

6. De Piero, A., Bassett, N., Rossi, A., \& Samman, N. (2015). Trends in Food Consumption of University Students. Nutricionhospitalaria, 1824-1831.

7. Garza, K., Ding, M., Owensby, J., \& Zizza , C. (2016). Impulsivity and fast-food consumption: A cross-sectional study among working adults. Journal of the Academy of Nutrition and Dietetics, $61-68$

8. Ismail, I. (2016). Trend of fast food consumption among university girls in Karachi, Pakistan.

9. Mirkarimi, K., Mansourian, M., Kabir, M. J., Eri, M., Hosseini, S. G., Qorbani , M., . . Davaji, R. O. (2016). Fast Food Consumption Behaviors in High-School Students based on the Theory of Planned Behavior (TPB).

10. Oexle, N., Barnes, T., Blake, C., Bell, B., \& Liese, A. (2015). Neighborhood Fast Food Availability and Fast Food Consumption. Appetite, 227-232. 